\title{
ORIGEM E TEOR DA PRODUÇÃO DO CONHECIMENTO COM BASE EM TESES E DISSERTAÇÕES NACIONAIS SOBRE CUSTOS NO SETOR PÚBLICO
}

\section{THE ORIGIN AND CONTENT OF KNOWLEDGE PRODUCTION ON COSTS IN THE PUBLIC SECTOR IN BRAZILIAN THESES AND DISSERTATIONS}

\section{ORIGEN Y CONTENIDO DE LA PRODUCCIÓN DEL CONOCIMIENTO A PARTIR DE TESIS Y DISERTACIONES NACIONALES SOBRE COSTOS EN EL SECTOR PÚBLICO}

Resumo: A importância da gestão de custos no setor público tem se tornado cada vez mais evidente à medida que se observa sua contribuição para o processo decisório, o controle gerencial, a elaboração de planejamento e 0 aumento da eficiência na prestação do serviço público. 0 presente trabalho buscou identificar a origem e o teor da produção do conhecimento com base em teses e dissertações que se propuseram a investigar a temática de custos no setor público. Para tanto, foi realizada uma pesquisa bibliográfica na Biblioteca Digital Brasileira de Teses e Dissertações, onde foram localizados 41 trabalhos na área. Após a análise dos trabalhos, identificou-se, entre outros fatores, que: a partir de 2005, houve crescimento na quantidade de pesquisas sobre a temática; a origem dos estudos é, principalmente, da área de Administração e Contabilidade; a Saúde e a Educação destacam-se entre as áreas de aplicação das pesquisas; a maioria das pesquisas tem como escopos a realização de diagnóstico em organização, o levantamento de informações de custos e a proposta de um sistema de custos. Por fim, foi possível identificar lacunas e oportunidades de desenvolvimento de futuras pesquisas.

Palavras-chave: Origem; teor; teses; dissertações; custos no setor público.

Amanda Finck Drehmer - amandadrehmer@gmail.com

Mestranda em Administração de Empresas pela Universidade do Estado de Santa Catarina - Florianópolis - SC, Brasil

Fabiano Maury Raupp - fabianoraupp@hotmail.com

Professor da Universidade do Estado de Santa Catarina, Escola Superior de Administração e Gerência - Florianópolis - SC, Brasil

Artigo submetido no dia 17.03.2015 e aprovado em 22.07.2016.

DOI: http://dx.doi.org/10.12660/cgpc.v21n69.60047 


\section{Abstract}

The importance of cost management has become increasingly evident as its contribution to the decision-making process and its role in controlling, planning and increasing efficiency in the provision of public services have become more apparent. This paper aims to identify the origin and content of knowledge production in those Brazilian theses and dissertations that deal specifically with costs in the public sector. A total of 41 such theses were found following a bibliographic search through the Brazilian Digital Library of Theses and Dissertations. After analyzing the data, we found the following: From 2005 onwards, the quantity of research on the aforementioned theme experienced a significant increase; the majority of these theses and dissertations originated in the field of Management and Accounting; Healthcare and Education were the most popular fields for research development; most of this research used a similar format whereby a corporate diagnostic was carried out, information on costs was gathered and a cost accounting system was proposed. Finally, it was possible to identify certain gaps and opportunities that offered the potential to develop future research on the subject.

Keywords: Origin; content; theses; dissertations; costs in the public sector.

\section{Resumen}

La importancia de la gestión de costos en el sector público resulta cada vez más evidente en la medida en que se observa su contribución para el proceso de decișión, el control gerencial, la elaboración del planeamiento y el aumento de la eficiencia en la prestación dél servicio público. El presente trabajo buscó identificar el origen y el contenido de la producción del conocimiento a partir de tesis y disertaciones que investigaron la temática de costos en el sector público. De esta manera, fue realizada una investigación bibliográfica en la Biblioteca Digital Brasileña de Tesis y Disertaciones, en la que fueron localizados 41 trabajos en esta área. Despues de analizar los trabajos, se identificaron, entre otros factores, que a partir del 2005 hubo un crecimiento en la cantidad de investigaciones sobre el asunto, el origen de los estudios y, principalmente, las áreas de Administración y Contabilidad, de Salud y Educación se destacan con relación a la aplicación de las investigaciones. La mayoría de las investigaciones tiene como objetivo la realización del diagnóstico en organización, la obtención de informaciones de costos y la propuesta de un sistema de costos. Finalmente, fue posible identificar espacios y oportunidades de desarrollo de futuras investigaciones.

Palabras clave: Origen; contenido; tesis; disertaciones; costos en el sector público.

\section{INTRODUÇÃO}

No decorrer dos últimos anos, a importância da gestão de gastos do governo tem se tornado cada vez mais evidente, principalmente em razão da escassez de recurso e do aumento da demanda na prestação de serviços públicos, que exigem do gestor público instrumentos que o auxiliem a alocar recursos públicos. Um estudo apresentado pelo Banco Nacional de Desenvolvimento Econômico e Social (BNDES, 2000) demonstrou, segundo dados empíricos, as dificuldades que os gestores públicos enfrentam no momento de reduzir gastos públicos, sendo necessário um sistema que demonstre os processos e seus custos, servindo de base para possíveis decisões, por exemplo, como redução de gastos. A realidade do es- tudo do BNDES demonstra, ao mesmo tempo, precariedades e potenciais de avanços na utilização de informações de custos no setor público. A gestão de custos é capaz de fornecer informações que auxiliam o processo decisório, o controle gerencial e que fundamentam o planejamento e a mensuração do resultado das atividades públicas. Para Mauss e Souza (2008), o estabelecimento de padrões no planejamento e a mensuração dos resultados podem viabilizar a avaliação do desempenho dos gestores e da entidade governamental, com o objetivo de demonstrar sua eficiência econômica.

A gestão de custos no setor público tem ganhado destaque também no âmbito acadêmico, com o aumento das produções sobre essa temática. No que diz respeito à avalia- 
ção da produção do conhecimento de custos no setor público, observa-se a existência de estudos que avaliam essa produção em artigos, como é o caso dos trabalhos de Scarpin, Söthe e Kreuzberg (2012), que analisam os artigos posteriores à publicação do estudo no 12 da International Federation of Accountants (IFAC), os de Carneiro et al. (2012), que fazem uma revisão focada na publicação de artigos científicos com base na promulgação da Lei de Responsabilidade Fiscal, e os de Filho e Peixe (2015), que fazem um levantamento bibliométrico das edições do congresso brasileiro de custos. Portanto, com vistas a estender as avaliações também para o âmbito das teses e dissertações, o presente trabalho tem o objetivo de identificar a origem e o teor da produção do conhecimento com base em teses e dissertações que se propuseram a investigar a temática de custos no setor público.

O artigo está estruturado em cinco seções, iniciando por esta introdução. A segunda seção contempla o referencial teórico, que abrange discussões sobre a produção do conhecimento em teses e dissertações, a importância da produção do conhecimento sobre custos no setor público e a evolução da legislação sobre o tema no contexto brasileiro. O percurso metodológico, apresentado na terceira seção, detalha os procedimentos utilizados na realização da pesquisa. A seção de resultados apresenta a origem e o teor da produção do conhecimento nas teses e dissertações levantadas. Na quinta e última seção são inferidas as considerações finais do trabalho.

\section{Fundamentos teóricos}

\subsection{Produção do conhecimento: o que se}

\section{espera das teses e dissertações?}

Segundo Leite Filho (2008), a produção do conhecimento tem como papel fundamental servir de referência para praticantes e estudiosos. Muitas das contribuições para a produção desse conhecimento vêm de professores, pesquisadores, mestres e doutores formados por programas de pós-graduação. Dessa forma, as publicações no âmbito desses programas, como teses e dissertações, podem contribuir para a percepção do estágio de desenvolvimento de determinada temática.

Martins e Theóphilo (2009) apontam dois sentidos para o vocábulo "tese". O primeiro refere-se à identificação de uma proposição com o intuito de ser defendida em público. $O$ segundo refere-se à tese como o trabalho científico propriamente dito, necessário para a obtenção do grau de "doutor". Algumas características fundamentais das teses seriam a demonstração de que o autor do trabalho é um estudioso capaz de avançar na disciplina à qual se dedica e a originalidade, no sentido de conhecer profundamente um assunto de forma a "descobrir" algo que não foi dito por outros estudiosos. Os autores explicam que essa originalidade não se refere às descobertas e invenções como as próprias das ciências naturais, e sim ao apontamento de um novo caminho, uma diferente perspectiva, que possa ser interessante a outros estudiosos da área.

A dissertação é o produto final de um curso de mestrado, em que o graduado busca enriquecer sua competência científico-profissional. Sendo assim, deverá "versar sobre um assunto específico, seguindo uma metodologia sustentada por outras pesquisas 
a respeito do tema, e acrescentar alguma contribuição à área em estudo" (Longaray \& Beuren, 2009, p. 42). Segundo Longaray e Beuren (2009), da dissertação esperam-se um pensamento amadurecido do educando e também uma preparação para o estágio mais avançado, o doutorado.

Dadas as especificidades de cada trabaIho, as teses e dissertações são tomadas, muitas vezes, como referências entre os estudos de suas respectivas áreas, por conterem boa fonte de informações para estudiosos que buscam novas alternativas, novos desenvolvimentos e novos olhares sobre o campo. Dessa forma, espera-se que apresentem metodologias fundamentadas e estruturadas. A busca pela utilização de teses e dissertações como referências em trabalhos acadêmicos delineia um processo de continuidade e aperfeiçoamento de determinados temas, indicando avanço no conhecimento (Rocha, 2012).

Tendo em vista a contribuição das teses e dissertações para o avanço das discussões sobre determinada temática, destaca-se a importância do desenvolvimento daquelas que abordem a gestão de custos no setor público e possam servir de base para implementar sistemas de custos no setor público. Alves Filho e Martinez (2006, p. 2) destacam benefícios que um sistema de gestão de custos pode propiciar ao setor público, como: poderia ampliar a avaliação de seus desempenhos econômico, financeiro e patrimonial, além de otimizar a função controle na tentativa de tornar mais transparente a comunicação de seus relatórios, resultantes de suas gestões em contraste com os programas de governo. Dessa forma, além do potencial das informações de custo da produção de bens e serviços públicos para o controle e a tomada de decisões, destaca-se também o potencial para tornar a administração pública mais transparente. Para Alonso (1999), a apuração dos custos dos serviços públicos e sua publicidade são importantes instrumentos de controle social, permitindo a avaliação da eficiência e economicidade dos serviços prestados.

Exemplos clássicos nessa área, que ilustram o potencial de contribuição da academia na utilização de sistemas de custos em órgão públicos, são as teses de Nelson Machado e Victor Holanda, que serviram de base conceitual para a elaboração do Sistema de Informações de Custos (SIC) no governo federal.

O processo de concepção, desenvolvimento e implantação do SIC estão sustentado em bases teóricas e conceituais, na abordagem sistêmica, na flexibilidade adaptativa, no gradualismo e na concomitância. No que tange às diretrizes teóricas conceituais, a principal referência é o trabalho de Nelson Machado (2002) intitulado: "Sistema de Informação de Custos: Diretrizes para Integração ao Orçamento Público e à Contabilidade Governamental'. Na parte da metodologia de desenvolvimento e implantação, valeu-se da abordagem oriunda da tese de Victor Holanda (2002): "Controladoria Governamental no Contexto do Governo Eletrônico _ Uma modelagem utilizando o enfoque sistêmico e a pesquisa-ação na Coordenadoria de Controle Interno da Secretaria da Fazenda do Estado de SP". Os trabalhos foram defendidos na FEA/USP e, não obstante, oriundos de reflexão teórica acadêmica, ambos foram também "experimentados" no governo do Estado de São 
Paulo entre os anos de 1996 e 2002 e ora replicados, em sua essência, no governo federal (período de 2004 a 2010) (Monteiro, 2010, p. 2).

O avanço da legislação e a obrigatoriedade de determinadas medidas podem impulsionar estudos sobre determinado fato. $\mathrm{Da}$ mesma forma, também os estudos e trabaIhos acadêmicos sobre o tema podem servir de base para elaborar a legislação. Sendo assim, a produção do conhecimento sobre custos no setor público pode estimular o avanço na regulamentação e obrigatoriedade da utilização de um sistema de custos nos órgãos públicos.

\subsection{A evolução na legislação sobre custos no setor público brasileiro}

A contabilidade de custos surgiu da necessidade de contadores, auditores e fiscais resolver seus problemas de mensuração monetária dos estoques e do resultado. Atualmente, a contabilidade de custos tem duas funções relevantes: auxílio ao controle, fornecendo dados para estabelecer padrões, orçamentos e outras formas de previsão, comparando-os com o efetivamente acontecido; ajuda para tomada de decisões, fornecendo informações das consequências de curto e longo prazos sobre medidas de introdução ou corte de produtos, administração de preços de venda, entre outros fatores (Martins, 2003).

Apesar de terem surgido no setor privado, as informações de custos têm grande potencial para serem utilizadas também no setor público. A evolução da sociedade e o surgimento da terceirização e da privatização das coisas públicas são eventos que exigem dos gesto- res públicos o conhecimento dos custos em suas entidades, "a fim de poderem tomar as melhores decisões entre as alternativas de produzir ou de comprar bens e serviços, de produzir ou privatizar serviços" (Slomski, 2011, p. 69). Diniz (2004, p. 26) destaca os constantes aumentos da demanda por serviços públicos sem um crescimento proporcional da receita.

Esse quadro exige do poder público a implementação de medidas de ampliação das fontes de recursos e redução nos gastos, de modo a não ser afetado o cumprimento das metas fiscais que, nestes últimos anos, tem sido uma das principais prioridades governamentais. Neste ponto, a gestão de custos no âmbito governamental é decisiva, pois é um instrumento essencial ao gestor público para a satisfação dos interesses públicos, da forma como prevê a administração pública gerencial.

Em termos de legislação, o controle de custos foi inicialmente previsto no setor público pela Lei no 4.320/64, art. 85, que expressa a determinação dos custos dos serviços industriais. A contabilidade pública brasileira é regulamentada por essa lei, que estatui normas gerais de direito financeiro para elaborar e controlar orçamentos e balanços da União, dos Estados, dos Municípios e do Distrito Federal (Brasil, 1964). Com vistas a se adequar às normas de contabilidade internacional e a tornar a administração pública mais eficiente, dois marcos impulsionaram alterações: a publicação da Lei de Responsabilidade Fiscal (LRF) e a publicação pela IFAC das International Public Sector Accounting Standard (IPSAS). 
A Lei de Responsabilidade Fiscal (Lei Complementar no 101, de 4 de maio de 2000) estabelece normas de finanças públicas voltadas para a responsabilidade na gestão fiscal. Para Borges, Mário e Carneiro (2011), as mudanças produzidas pela aplicação da LRF contribuíram para o saneamento das contas públicas e a reestruturação na capacidade de prestação dos serviços públicos e na promoção do bem-estar social. Em seu art. 50, § 30, expressa que "a Administração Pública manterá sistema de custos que permita a avaliação e o acompanhamento da gestão orçamentária, financeira e patrimonial". Já as IPSAS ou Normas Internacionais de Contabilidade para o Setor Público (NICSP) têm o objetivo de definir procedimentos uniformes, permitindo a uma entidade a comparabilidade de suas demonstrações contábeis atuais com períodos anteriores e também de demonstrações contábeis entre entidades distintas. Sendo assim, são estabelecidas diretrizes para a estrutura e os requisitos mínimos de conteúdo a ser apresentado (IFAC, 2010).

No Brasil, o Conselho Federal de Contabilidade, por meio da Resolução no 1.103/07, criou o Comitê Gestor da Convergência no Brasil, formado pelo Conselho Federal de Contabilidade (CFC), Instituto dos Auditores Independentes do Brasil (Ibracon), Comissão de Valores Mobiliários (CVM), Banco Central do Brasil (Bacen), Superintendência de Seguros Privados (Susep), Secretaria do Tesouro Nacional (STN) e Banco Nacional de Desenvolvimento Econômico e Social (BNDES). O Comitê buscou mais transparência das informações financeiras utilizadas pelo mercado, mediante reformas contábil e de auditoria, e foi responsável por elaborar um plano de ação para a conver- gência do sistema contábil brasileiro às normas internacionais de contabilidade.

Nessa busca pela convergência contábil, o Conselho Federal de Contabilidade, após audiência pública, aprovou por meio das Resoluções nos 1.128 a 1.137 , de 2008 , as Normas Brasileiras de Contabilidade Técnicas Aplicadas ao Setor Público (NBCASP) (Rosa, 2011). As NBCASP, conforme Darós e Pereira (2009), resgatam a essência da Ciência Contábil, qual seja a evidenciação das alterações no patrimônio da entidade.

O desprendimento do foco estritamente orçamentário ocorre, pois os efeitos dos registros contábeis devem ser evidenciados nas demonstrações contábeis do período com os quais se relacionam, independentemente do momento da execução orçamentária. Particularmente, a NBC T 16.2 estabelece a definição de patrimônio público e segrega o Sistema Contábil Público em cinco Subsistemas de Informações Contábeis, trazendo como inovação a criação do subsistema de custos.

Ainda objetivando a convergência às normas internacionais de contabilidade pública, o Ministério da Fazenda editou a Portaria no 184 , de 25 de agosto de 2008, dando competência à Secretaria do Tesouro Nacional (STN) para:

a) identificar as necessidades de convergência às normas internacionais de contabilidade publicadas pela IFAC e às normas brasileiras editadas pelo CFC;

b) editar normativos, manuais, instruções de procedimentos contábeis e Plano de Contas Nacional, objetivando a elaboração e publicação de demonstrações con- 
tábeis consolidadas, em consonância com os pronunciamentos da IFAC e com as normas do Conselho Federal de Contabilidade, aplicadas ao setor público; e c) adotar os procedimentos necessários para atingir os objetivos de convergência estabelecido no âmbito do Comitê Gestor da Convergência no Brasil (BRASIL, 2008).

Dessa forma, a Secretaria do Tesouro Nacional, tendo como marco teórico as NBCASP, em conjunto com a Secretaria de Orçamento Federal, publicou, por meio de Portaria Conjunta STN/SOF, o Manual técnico de contabilidade aplicada ao setor público. Segundo Rosa (2011), o manual visa promover a transparência das contas públicas e padronizar os procedimentos a serem utilizados pelas três esferas de governo, com vistas a garantir a consolidação das contas públicas.

Três anos após o surgimento das Normas Brasileiras de Contabilidade Aplicadas ao Setor Público, em 2011, o Conselho Federal de Contabilidade aprovou a NBC T 16.11, que estabelece a conceituação, o objeto, os objetivos e as regras básicas para mensurar e evidenciar os custos no setor público, apresentada como Sistema de Informação de Custos do Setor Público (SICSP). Segundo a norma, o SICSP tem por objetivo:

a) mensurar, registrar e evidenciar os custos dos produtos, serviços, programas, projetos, atividades, ações, órgãos e outros objetos de custos da entidade;

b) apoiar a avaliação de resultados e desempenhos, permitindo a comparação entre os custos da entidade com os custos de outras entidades públicas, estimu- lando a melhoria do desempenho dessas entidades;

c) apoiar a tomada de decisão em processos, tais como comprar ou alugar, produzir internamente ou terceirizar determinado bem ou serviço;

d) apoiar as funções de planejamento e orçamento, fornecendo informações que permitam projeções mais aderentes à realidade com base em custos incorridos e projetados;

e) apoiar programas de controle de custos e de melhoria da qualidade do gasto (CFC, 2012).

A implementação do SICSP deve levar em consideração os objetivos organizacionais e as características locais, sendo o processo sistemático e gradual. A Portaria no 406/2011, da Secretaria do Tesouro Nacional, que aprovou a $4^{\text {a }}$ edição do Manual de contabilidade aplicada ao setor Público, estabeleceu o início de 2013 como prazo para a adoção do sistema de custos por todos os entes federativos. Ainda no mesmo ano, a Portaria no 828/2011 da Secretaria do Tesouro Nacional alterou o prazo para o final do exercício de 2014. Durante o prazo de transição, foram também previstos a publicação, pelos entes da federação, dos procedimentos contábeis patrimoniais e específicos postos em prática e um cronograma dos procedimentos que ainda seriam realizados (Brasil, 2011).

\section{Percurso metodológico}

Por se tratar de pesquisa que utiliza como fonte de dados a literatura sobre o tema, identifica-se o presente trabalho como um estudo bibliométrico. Segundo Daim et al. (2008), a análise bibliométrica busca pa- 
drões para explicar comportamentos não estruturados. Portanto, auxilia processos de tomada de decisões ao organizar e analisar grandes massas de dados de forma estruturada. A técnica foi empregada no presente trabalho buscando visualizar o estado da arte das pesquisas na temática. Uma das contribuições dessa análise é a identificação de temas que necessitam de evidências, contribuindo para a orientação de investigações futuras.

Quanto aos objetivos, classifica-se como descritiva, pois visa descrever as características de determinada população ou fenômeno. Em relação aos procedimentos técni$\cos$, trata-se de uma pesquisa bibliográfica, desenvolvida com base em material já elaborado, constituído, nesse caso, de teses e dissertações (Gil, 2010).

O levantamento do material bibliográfico foi realizado na Biblioteca Digital Brasileira de Teses e Dissertações (BDTD), que é mantida pelo Instituto Brasileiro de Informação em Ciência e Tecnologia (IBICT) e tem o objetivo de reunir, em um só portal de busca, as teses e dissertações defendidas em todo o País e por brasileiros no exterior.

A busca pelas teses e dissertações que abordam a problemática de custos no setor público deu-se mediante a utilização da seguinte string: (custo OR sistema de custos OR método de custeio OR gestão de custos) AND (administração pública OR setor público). A inserção da string na busca pelo método tradicional resultou em 476 trabalhos, dos quais, após análise de título, área de conhecimento, resumo e sumário, 37 foram selecionados por abordar prioritariamente a temática de custos no setor público. Em seguida, com a intenção de reduzir a probabilidade de não inclusão de alguma tese ou dissertação pela não identificação segundo o método de pesquisa inicial, foi feita uma série de combinações no filtro avançado, utilizando-se as palavras-chave que compõem a string, quais sejam: custo; sistema de custos; método de custeio; gestão de custos; administração pública; setor público. Nessas diversas pesquisas, observou-se o aparecimento de teses e dissertações já selecionadas e, por fim, foram encontrados quatro trabalhos que não haviam sido localizados na busca inicial. Dessa forma, chegou-se a uma quantidade final de 41 publicações na área. Dado o interesse de incluir na pesquisa todas as teses e dissertações nacionais já publicadas na temática, não houve delimitação de período na busca.

Com o acesso ao texto completo das teses e dissertações selecionadas, pode-se proceder à análise do perfil dos trabalhos na área, mediante o levantamento de informações relacionadas à origem e ao teor das teses e dissertações. Quanto à origem, contemplaram-se ano de publicação do trabalho, universidade de origem e área de conhecimento do programa de pós-graduação em que está vinculado. Quanto ao teor, contemplaram-se área de aplicação da pesquisa, palavras-chave utilizadas e escopo das pesquisas.

As informações relacionadas à origem foram obtidas por meio da observação das páginas iniciais dos trabalhos. Já as informações relacionadas ao teor foram obtidas mediante análise dos resumos e, principalmente, dos objetivos. Nos casos em que nem o resumo nem os objetivos deixaram claros a área de aplicação ou o escopo da pesquisa, procedeu-se à consulta das considerações finais 
do trabalho.

\section{Análise dos resultados}

4.1 Origem: de onde vêm as teses e dissertações nacionais sobre custos no setor público
Conforme mencionado na metodologia do presente trabalho, não houve delimitação de data no momento da pesquisa por teses e dissertações. Sendo assim, pode-se observar que o desenvolvimento de trabalhos na temática é relativamente recente, uma vez que o mais antigo trabalho encontrado na BDTD data de 1999 (Figura 1).

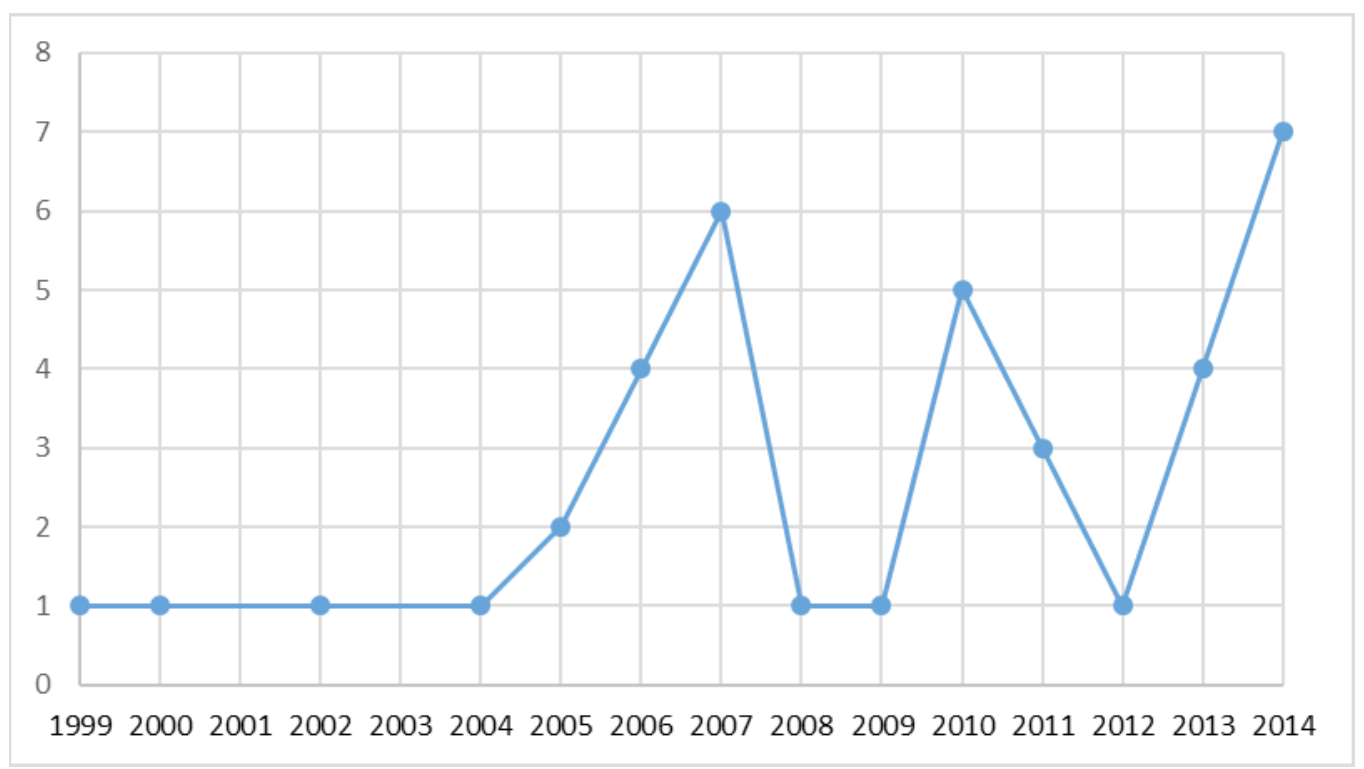

Fonte: dados da pesquisa (2015).

Figura 1. Ano de publicação das teses e dissertações.

Houve aumento na quantidade de estudos a partir de 2005, destacando-se os anos de 2007, 2010 e 2014 com, respectivamente, seis, cinco e sete trabalhos publicados. Foram encontrados três trabalhos com data de publicação em 2015, porém, como a pesquisa foi realizada em agosto do referido ano, optou-se por excluí-lo da contagem, dada a condição de parcialidade da informação.

Cabe aqui destacar os grandes marcos na evolução da legislação sobre custos no setor público, quais sejam: a publicação das NBCASP em 2008 e a da NBC T 16.11 e da Portaria 406 da STN, ambas em 2011. Ao considerar que a maioria dos trabalhos levantados nessa pesquisa são dissertações, que levam aproximadamente dois anos para serem publicadas a partir da data de definição de seu tema, infere-se que esses marcos podem ter tido influência no aumento das pesquisas sobre a temática. As NBCASP publicadas em 2008 podem ter refletido um aumento para cinco publicações em 2010. Já a NBC T 16.11 e a definição de prazo para adoção de sistema de custos por todos os entes federativos, ocorridas em 2011, podem ter refletido no crescimento em 2013 das publicações em relação ao ano anterior e na tendência de crescimento também para os anos seguintes. A produção dos 41 trabalhos analisados ocorreu em 14 diferentes universidades (Figura 2). 


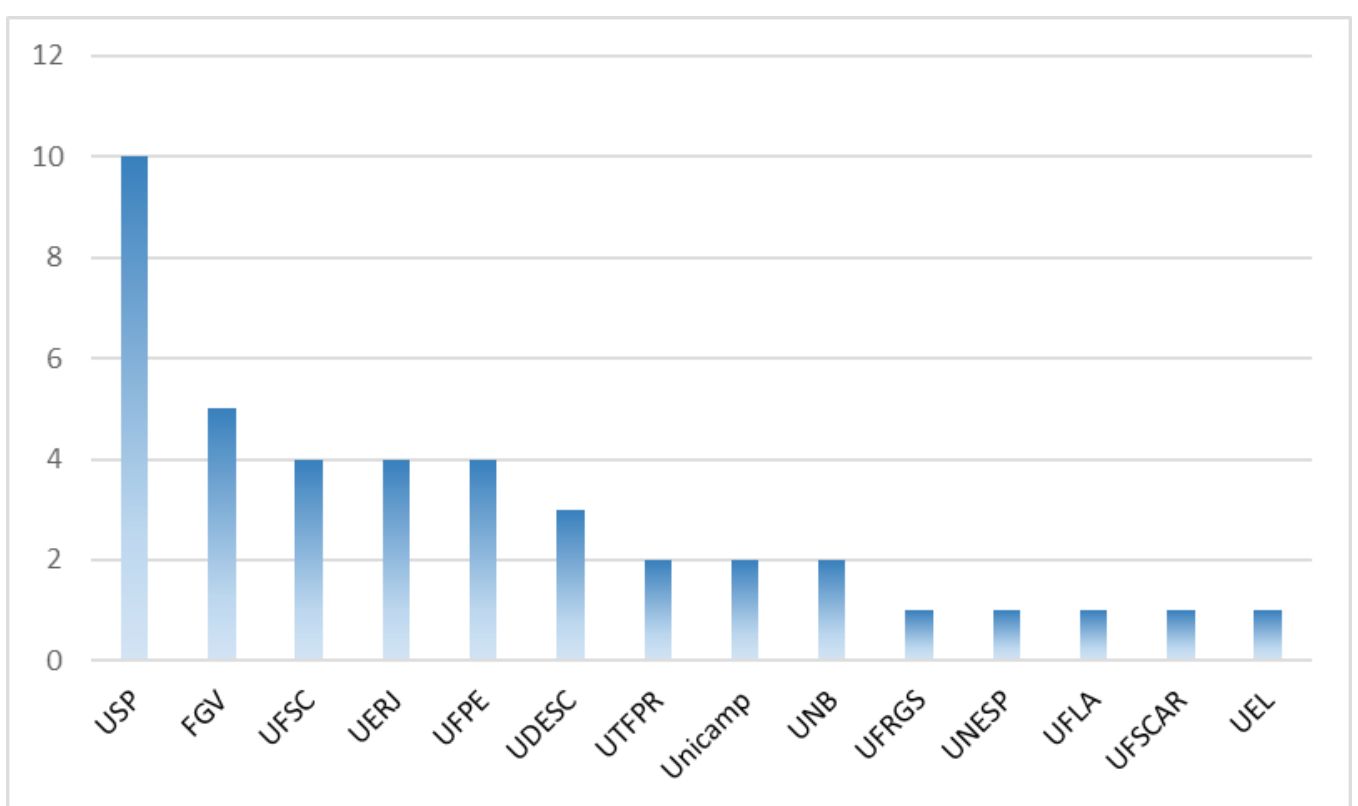

Fonte: Dados da pesquisa (2015).

Figura 2. Universidade de origem das teses e dissertações.

A Universidade de São Paulo (USP) destaca-se como a que mais produziu trabalhos sobre gestão de custos no setor público, em diferentes programas, como segue: Pós-Graduação em Controladoria e Contabilidade, Administração, Medicina, Enfermagem, entre outros. Em seguida, aparece a Fundação Getulio Vargas (FGV) com cinco publicações e a Universidade Federal de Santa Catarina (UFSC), Universidade do Estado do Rio de Janeiro (UERJ) e Universidade
Federal de Pernambuco (UFPE), todas com quatro publicações na área.

Dos 41 trabalhos desenvolvidos na temática, 35 são dissertações elaboradas em cursos de mestrado e seis são teses desenvolvidas em cursos de doutorado. Dos Programas de Pós-Graduação aos quais os trabalhos estão vinculados, destaca-se a área de Administração e Contabilidade (Figura 3).

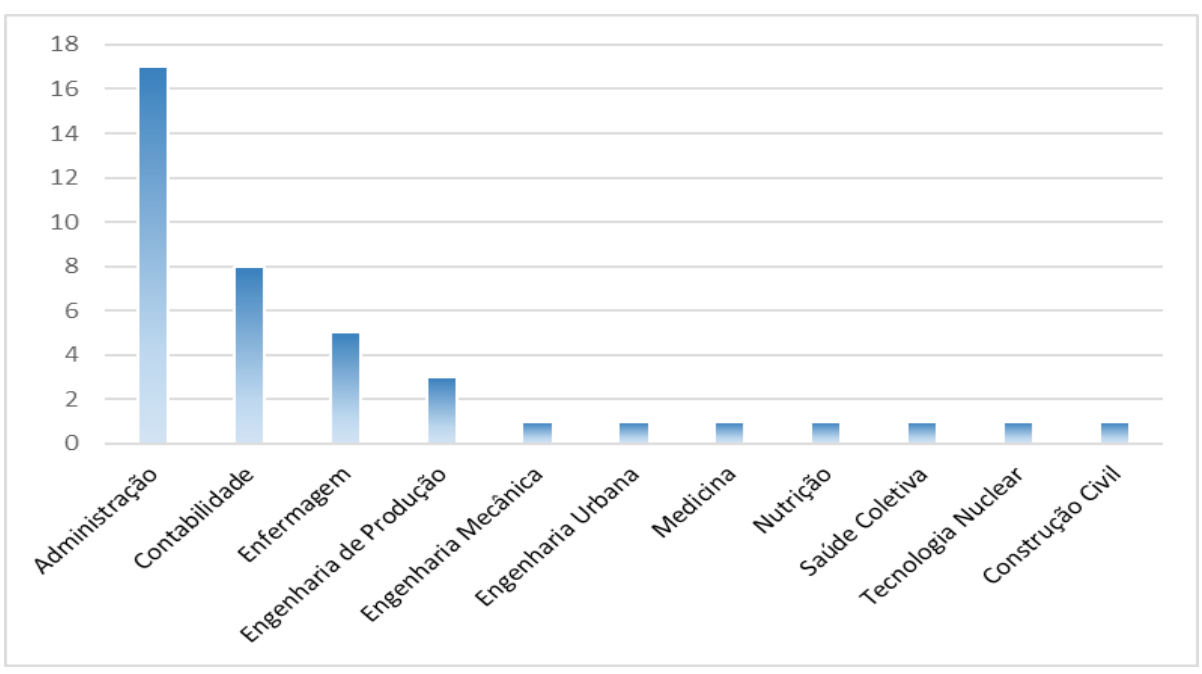

Fonte: Dados da pesquisa (2015).

Figura 3. Área de conhecimento das teses e dissertações. 
Em sua maioria, os Programas de Pós-Graduação na área de Administração são ligados à Administração Pública. Estão incluídas nessa área pós-graduações em Planejamento e Governança Pública, Administração de Empresas, Gestão e Políticas Públicas, Gestão Pública, Administração Pública, Administração e Gestão Empresarial. A segunda área de conhecimento que mais produziu trabalhos na temática de custos no setor público é a Contabilidade, com trabalhos provenientes de Programas de Pós-Graduação em Ciências Contábeis e em Controladoria e Contabilidade. Destacam-se também os trabalhos produzidos na Pós-Graduação em Enfermagem, tratando de custos na área da Saúde Pública, e na Pós-Graduação em En- genharia de Produção.

\subsection{Teor das teses e dissertações}

No que diz respeito ao teor das teses e dissertações selecionadas, procedeu-se ao levantamento das palavras-chave utilizadas, das áreas em que as pesquisas foram desenvolvidas e do escopo das pesquisas.

As mais variadas expressões foram encontradas nas palavras-chave dos trabalhos. Porém, com o auxílio de ferramenta de contagem de palavras, procurou-se evidenciar as palavras mais utilizadas, seja de forma avulsa, seja dentro da expressão (Figura 4).

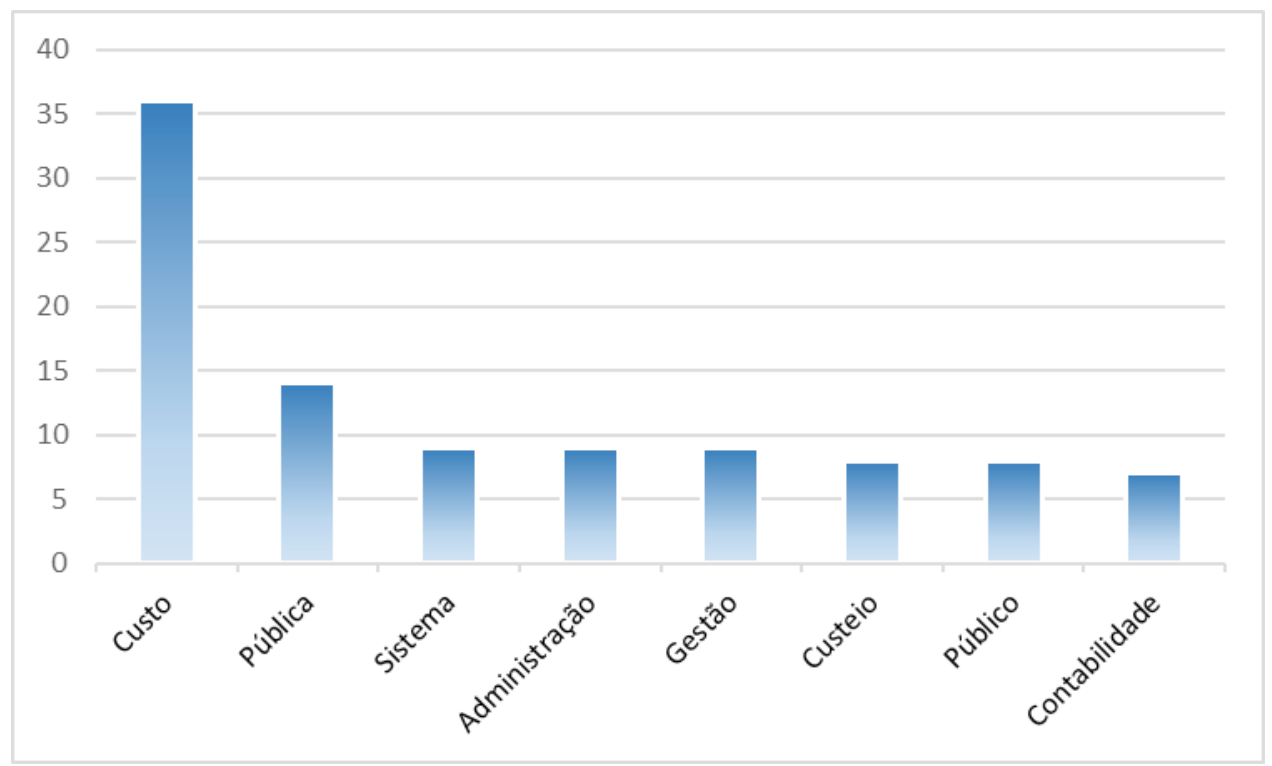

Fonte: Dados da pesquisa (2015).

Figura 4. Palavras-chave utilizadas nas teses e dissertações.

A palavra "custo" teve 36 ocorrências, sendo 28 em sua forma plural (custos) e 8 em sua forma singular (custo). A palavra "custeio" apareceu oito vezes, entre as quais se destaca sua utilização uma vez na expressão "custeio por absorção" e quatro vezes em "custeio ABC". A palavra "pública" foi a se- gunda com mais quantidade de ocorrências, sendo utilizada nas expressões "gestão pública", "administração pública" e "contabilidade pública", o que justifica a significativa ocorrência das palavras "gestão", "administração" e "contabilidade"; essa última também apareceu nas expressões "contabilida- 
de governamental,' "contabilidade de custos" e "contabilidade de custeio." A palavra "público" também é bastante utilizada na expressão "setor público". Por fim, aliada a palavra "custos", observou-se expressiva ocorrência da palavra "sistema", nas expressões "sistema de informação de custos", "sistema(s) de custos", "sistema de custeio" e "sistema de apuração de custos".

Quanto à definição do local de desenvolvimento dos trabalhos, a área da saúde é a que tem atraído mais atenção dos pesquisadores (Figura 5).

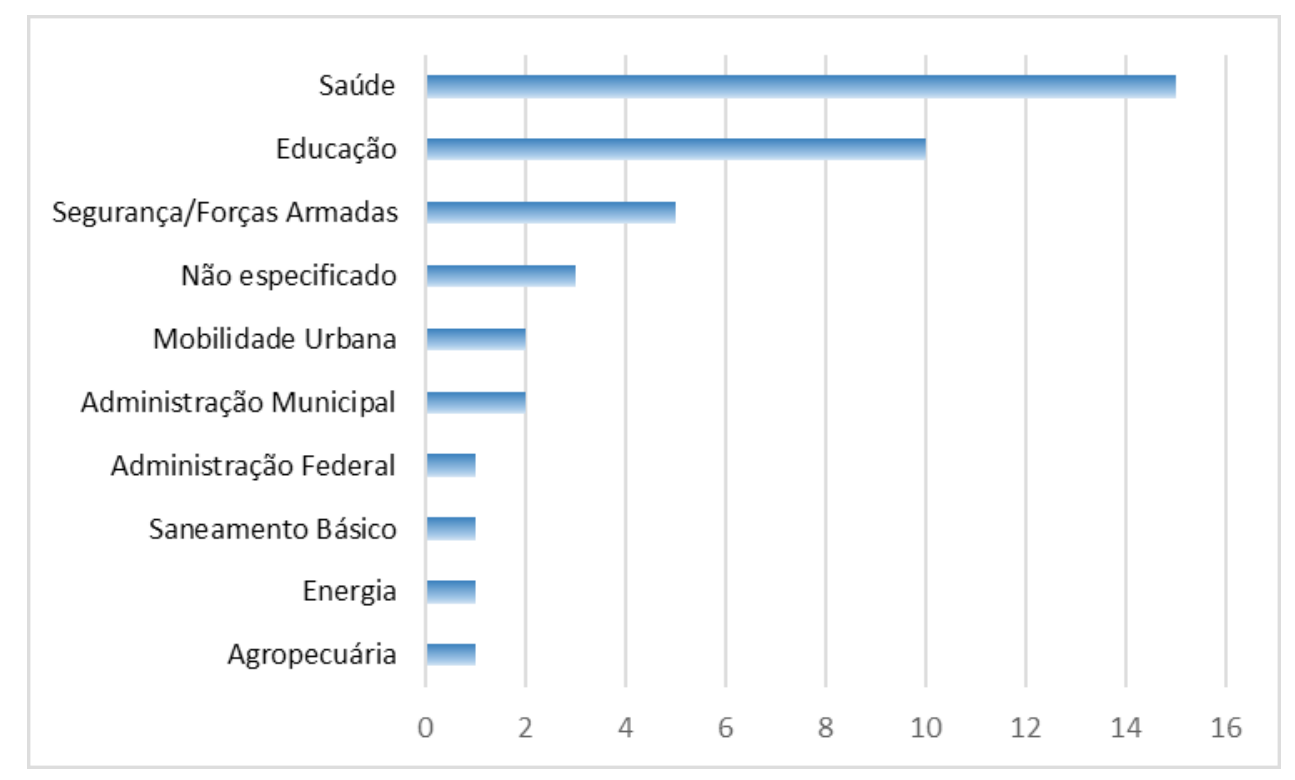

Fonte: dados da pesquisa (2015).

Figura 5. Área de aplicação da pesquisa.

Foram desenvolvidos trabalhos nas seguintes áreas: saúde, educação, segurança/ Forças Armadas, agropecuária, energia, saneamento básico, administração municipal, administração federal e mobilidade urbana. Alguns trabalhos, aqui classificados como "Não especificado", não apresentam aplicação em uma área específica, como é o caso de um trabalho que propôs um modelo geral de avaliação de desempenho dos gastos públicos, em que o autor do estudo cita que adaptações no modelo foram discutidas com representantes de diversos setores da sociedade e de todos os poderes. Aproximadamente $37 \%$, ou seja, 15 trabalhos, foram desenvolvidos na área da saúde, sendo a maioria em hospitais públicos. A área da educação representa $24 \%$ dos trabalhos realizados, os quais foram desenvolvidos em universidades, institutos federais, escolas e creches. A área de segurança/Forças Armadas também apresentou quantidade expressiva de estudos, representando $12 \%$ das teses e dissertações levantadas.

Em âmbito federal, observou-se a presença de um estudo aplicado ao Poder Judiciário federal. No que diz respeito aos órgãos da administração direta municipal, foram identificados dois estudos que procuraram verificar o uso das informações de custos no processo de tomada de decisão, pelos gestores das vinte secretarias municipais da saúde do estado de Santa Catarina, e investigar a per- 
cepção dos usuários sobre a importância do SIC no setor público para a gestão e o desenvolvimento municipal.

Com base na análise do conteúdo e no objetivo das teses e dissertações, estas foram classificadas em oito principais escopos de pesquisa, quais sejam: diagnóstico em organização; levantamento de informações de custos; proposta de sistema de custos; implementação de sistema na organização; análise de cenário; desenvolvimento e validação de modelo global; análise do SIC do governo federal, entre outros (Figura 6).

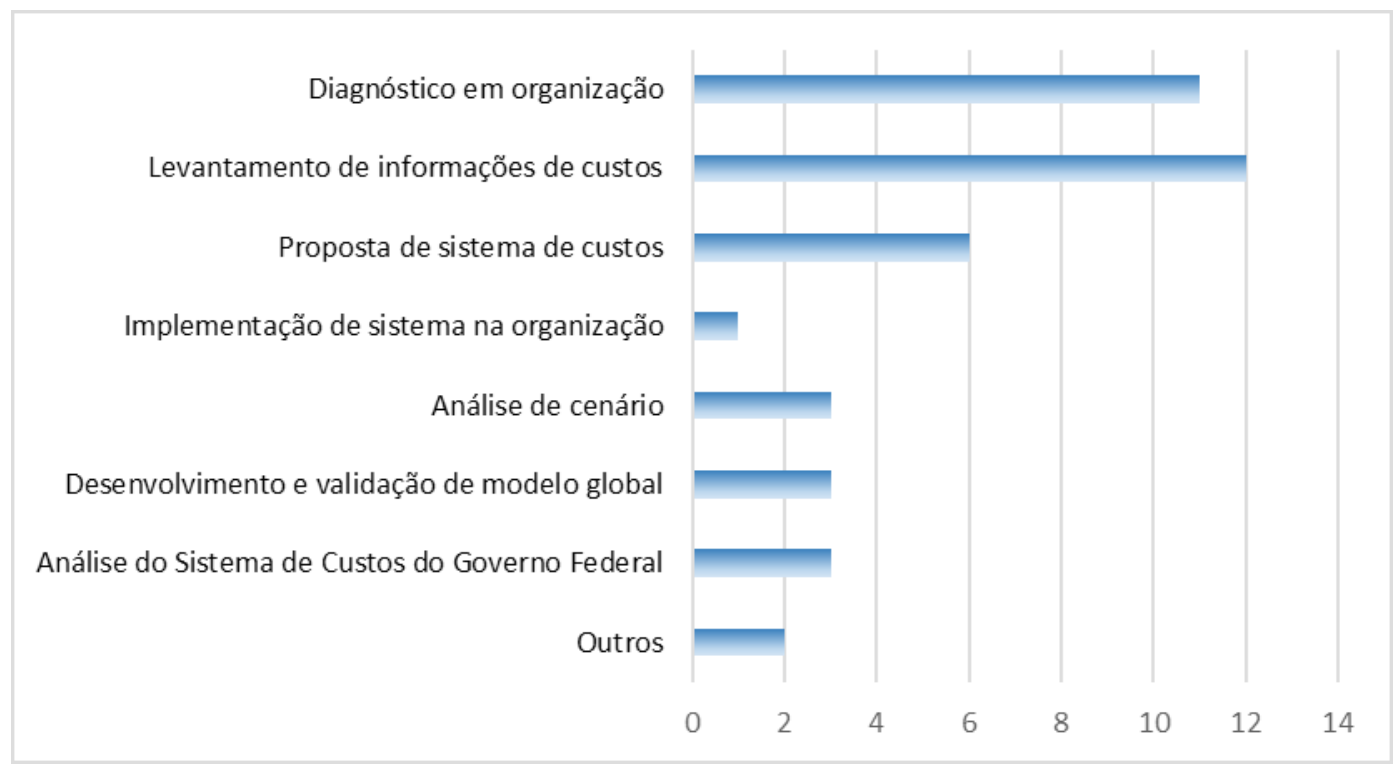

Fonte: dados da pesquisa (2015).

Figura 6. Escopo das pesquisas.

Dos 41 estudos, 11 trabalharam com diagnóstico em uma organização, analisando a forma como esta trabalhava as informações de custo. Nesse aspecto, diversas abordagens foram tomadas, como: identificação de qual método de custeio é utilizado pela organização; comparação do sistema utilizado com outros possíveis métodos a serem adotados; levantamento de benefícios trazidos pelas informações de custos; análise da confiabilidade das informações; análise de fatores que facilitam e dificultam a implementação do sistema; impactos gerados na organização.

O levantamento de informações de custos foi realizado em 12 trabalhos, que, no geral, buscaram o custo de um processo ou a atividade em específico. Alguns exemplos incluem: cálculo do custo-aluno em creches municipais e universidades; custo de refeições em determinada unidade; custo da coleta de resíduos sólidos domiciliares; custo dos subprocessos do manejo de resíduos de serviços de saúde em hospital público; custo da contratação de obra por universidade pública, entre outros.

Verificou-se, ainda, que 6 dos 41 trabalhos propuseram um sistema de custos e alguns deles implementaram um piloto em determinado departamento com o objetivo de 
validar a proposta. Esse foi o caso dos seguintes estudos: proposição da utilização do sistema $A B C$ pelo Detran (AL); aplicação do $A B C$ no Centro de Materiais de Esterilização do hospital; proposição de um modelo de custos para a Justiça Federal de Sergipe; implementação do custeio $A B C$ na seção de fiscalização do Aeroporto Internacional Tancredo Neves. Apenas um trabalho implementou um sistema de custos em uma organização como um todo. Trata-se da tese que aplicou um modelo baseado na concepção do sistema $A B C$ no Hospital Universitário Clemente de Faria.

A análise de cenário refere-se a trabalhos que tiveram o objetivo de visualizar a situação dos estudos e a utilização da gestão de custos. Foram encontradas três dissertações com esse perfil: pesquisa do processo de implementação de sistema de custos nos cenários nacional e internacional; análise dos estudos sobre custos em unidades básicas de saúde; verificação do uso de informações de custos em secretarias municipais da saúde do estado de Santa Catarina.

Observou-se a existência de três teses que trouxeram desenvolvimento de um modelo para aplicação em todo o setor, contudo implementado em órgão específico como forma de validação. Os modelos desenvolvidos pelas teses são: simulador de custos para planejamento de sistemas públicos de educação básica; instrumento de avaliação de custos nos serviços públicos de atenção básica à saúde; sistemática de avaliação de desempenho dos gastos públicos.

Três trabalhos dedicaram-se à análise do SIC do governo federal, verificando: sua contribuição como ferramenta de gestão e planejamento para o desenvolvimento de municípios; sua contribuição para produzir informações gerenciais que subsidiem a tomada de decisão de gestores da Polícia Federal; nível de aderência do SIC às teorias de contabilidade de custos.

Por fim, dois trabalhos não se enquadraram em nenhuma das linhas de estudos elencadas. Os objetivos deles foram: analisar a participação das enfermeiras no gerenciamento de custos de hospitais em São Paulo; fornecer subsídios para o processo de gestão de custos em serviços públicos de alta complexidade hospitalar.

\section{Considerações finais}

Na presente pesquisa, buscou-se identificar a origem e o teor da produção do conhecimento em teses e dissertações nacionais que abordam a temática de custos no setor público. Os dados detalhados neste trabalho demonstram que a discussão sobre a utilização de informações de custos no setor público é relativamente recente. Apenas a partir de 2005 houve um crescimento na quantidade de pesquisas sobre a temática, sendo o trabalho mais antigo identificado em 1999.

A tendência de crescimento das pesquisas ao longo da última década aponta para uma maior atenção dos pesquisadores sobre o tema, acompanhado também pela maior atenção dos legisladores brasileiros. Percebe-se que as pesquisas seguem a mesma tendência da legislação sobre o tema no Brasil, possivelmente impulsionadas pela publicação da Lei de Responsabilidade Fiscal em 2000, das Normas de Contabilidade Aplicadas ao Setor Público em 2008 e da Portaria no 406 da STN em 2011. 
Os estudos realizados até o presente momento têm sua origem, principalmente, em Programas de Pós-Graduação na área de Administração e Contabilidade. Tal fator é considerado natural dado que a temática pesquisada une a contabilidade de custos e a administração pública. Destaca-se, porém, a contribuição dos Programas de Pós-Graduação em Enfermagem, que abordam o tratamento dos custos geralmente em hospitais públicos. Essa união de custos no setor público com os cursos de enfermagem é compreendida ao se observar o alto interesse no desenvolvimento de estudo na área da saúde. Dos trabalhos analisados, $37 \%$ foram desenvolvidos na área da Saúde, 24\%, na Educação e 12\%, na área de Segurança/Forças Armadas. Saúde, Educação e Segurança são áreas que historicamente têm despertado o interesse da população e, ao mesmo tempo, exigem altos investimentos governamentais. Sendo assim, considera-se importante o desenvolvimento de trabalhos que contribuam para o levantamento de informações de custos nas áreas da Saúde, Educação e Segurança, auxiliando na melhor alocação de recursos.

Por outro lado, a concentração de trabalhos nessas áreas demonstra uma lacuna no desenvolvimento de estudos em outros setores, como mobilidade urbana, saneamento básico e em órgãos da administração federal, estadual e municipal. Nas administrações federal e municipal foram localizados, respectivamente, um e dois trabalhos. Das teses e dissertações analisadas, nenhuma foi realizada em órgão da administração direta estadual.

Tendo em vista a obrigatoriedade da adoção de um sistema de custos por todos os entes federativos, entende-se a escassez de estudos nos órgãos da administração direta da União, estados e municípios como uma lacuna que precisa ser preenchida. Vale destacar ainda que dos trabalhos realizados em órgãos da administração direta, apenas dois são aplicações em órgãos do Poder Executivo, o que representa $5 \%$ da totalidade de teses e dissertações analisadas.

Quanto ao escopo das pesquisas, observou-se que a maioria dos trabalhos inclui estudos de caso desenvolvidos em organizações específicas. Tais estudos buscaram desenvolver na organização: a avaliação do sistema de custos existente; o levantamento de informações de custos; a proposta de um novo sistema de informações de custos; ou a implementação parcial de um sistema de custos em determinado departamento da organização. Poucos foram os trabalhos que saíram do universo específico de uma organização para fazer uma análise de cenário mais global. Das teses e dissertações levantadas, apenas três fazem uma análise da situação brasileira no que diz respeito à utilização de informações de custos. Uma dissertação trata da análise dos estudos sobre custos em unidades básicas de saúde, restando dois trabalhos que analisam a situação, na prática, do uso das informações de custo. Um deles considerou o processo de implementação de sistema de custos nos cenários nacional e internacional e outro, em secretarias municipais.

Visualizou-se ainda a importância do SIC do governo federal, que foi objeto de estudo de três dissertações, o que justificou, até mesmo, a criação de uma categoria de escopo de pesquisa. 
Chama atenção também a pequena quantidade de trabalhos que implementam um sistema de custos em uma organização como um todo. Ressalta-se a complexidade dos fatores envolvidos na implementação de um sistema de custos em todos os setores de uma mesma organização, tendo apenas uma tese de doutorado tal proposta.

Isto posto, para trabalhos futuros, propõe-se a seguinte agenda de pesquisas:

a) Análise do estágio de adequação às normas e utilização de informações de custos pelo entes federativos, em âmbito federal, estadual ou municipal;

b) Levantamento de informações de custos em órgãos das administração federal, estadual e municipal, auxiliando-os no cumprimento da obrigatoriedade de implementação de sistema de custos;

c) Apontamento de facilidades e dificuldades encontradas no processo de implementação de sistemas de custos no setor público;

d) Implementação de sistema de custos em organizações como um todo;

e) Identificação da utilização de informações de custos em setores menos explorados, como mobilidade urbana, saneamento básico, agropecuária e energia.

Dado o potencial da academia em estimular a utilização na prática de informações de custos pelos órgãos públicos, cabe destacar a importância do desenvolvimento de estudos sobre custos no setor público. Sendo assim, espera-se que o presente trabalho oriente e estimule o desenvolvimento de futuras pesquisas na área, contribuindo para o crescimento de estudos em setores e te- mas ainda pouco explorados.

\section{Referências}

Alonso, M. (1999). Custos no serviço público. Revista do Serviço Público, 50(1), 37-63.

Alves Filho, E. M., \& Martinez, A. L. (2006). Gestão de custos numa secretaria municipal de educação. Anais do Congresso Brasileiro de Custos, Belo Horizonte, MG, Brasil, 13.

Banco Nacional de Desenvolvimento Econômico e Social. (2000). Uma introdução à contabilidade pública de custos. Informe-se, n. 18, ago, 2000. Recuperado de http:// www.bndes.gov.br/SiteBNDES/export/sites/ default/bndes_pt/Galerias/Arquivos/conhecimento/informesf/inf_18.pdf

Brasil. Lei no 4.320, de 17 de março de 1964. (1964). Estatui normas de direito financeiro para elaboração e controle dos orçamentos e balanços da União, dos Estados, dos Municípios e do Distrito Federal. Brasília, DF.

Brasil. Portaria no 184, de 25 de agosto de 2008. (2008). Dispõe sobre as diretrizes a serem observadas no setor público (pelos entes públicos) quanto aos procedimentos, práticas, elaboração e divulgação das demonstrações contábeis, de forma a torná-los convergentes com as Normas Internacionais de Contabilidade Aplicadas ao Setor Público. Brasília, DF.

Brasil. Lei Complementar no 101, de 4 de maio de 2000. (2000). Estabelece normas de finanças públicas voltadas para a responsabilidade na gestão fiscal e dá outras providências. Brasília, DF. 
Brasil. Portaria no 828, de 14 de dezembro de 2011. (2011). Altera o prazo de implementação do Plano de Contas Aplicado ao Setor Público e dá outras providências. Brasília, DF.

Borges, T. B., Mário, P. C., \& Carneiro, R. (2011). A implementação do sistema de custos proposto pelo governo federal: uma análise sob a ótica institucional. Anais do Congresso Brasileiro de Custos, Rio de Janeiro, RJ. Brasil, 18.

Carneiro, A. de F. et al. (2012). Custos na Administração Pública: revisão focada na publicação de artigos científicos a partir da promulgação da Lei de Responsabilidade Fiscal. Revista Contemporânea de Contabilidade, 9(18), 3-22.

Conselho Federal De Contabilidade. (2012). Normas brasileiras de contabilidade: contabilidade aplicada ao setor público: NBCs T 16.1 a 16.11. Recuperado de http://portalcfc.org.br/wordpress/wp-content/uploads/2013/01/Setor_P\%C3\%BAblico.pdf

Daim, T. U., Ploykitikoon, P., Kennedy, E. \& Choothian, W. (2008). Forecasting the future of data storage: case of hard disk drive and flash memory. Emerald Group Publishing Limited.

Darós, L. L., \& Pereira, A. S. (2009). Análise das Normas Brasileiras de Contabilidade Aplicadas ao Setor Público - NBCASP: mudanças e desafios para a contabilidade pública. Anais do Congresso USP de Iniciação Científica, São Paulo, SP. Brasil, 6.

Diniz, J. A. (2004). Percepções de gestores e assessores contábeis da Administração
Pública sobre aspectos do sistema de custos e resultados: uma análise em prefeituras municipais do Estado da Paraíba. (Dissertação de Mestrado em Ciências Contábeis). Universidade Federal da Paraíba, Paraíba, Brasil.

Filho, C. R., \& Peixe, B. S. (2015). Custos e avaliação de desempenho no setor público: um levantamento bibliométrico das edições do congresso brasileiro de custos. Anais do Congresso Brasileiro de Custos, Foz do Iguaçu, Brasil, 22.

Gil, A. C. (2010). Como elaborar projetos de pesquisa. São Paulo: Atlas.

International Federation of Accountants. (2010). Normas Internacionais de Contabilidade para o Setor Público. Recuperado de http://www.cnm.org.br/contadores/img/pdf/ normas_internacionais_de_contabilidade/ NornasInternacionaisdeContabilidadeparaoSetorPublico.pdf

Leite Filho, G. A. (2008). Padrões de produtividade de autores em periódicos e congressos na área de contabilidade no Brasil: um estudo bibliométrico. Revista de Administração Contemporânea, 12(2), 533-554.

Longaray, A. A., \& Beuren, I. M. (2009). Caracterização da pesquisa em contabilidade. In: Beuren, I. M. (org.). Como elaborar trabaIhos monográficos em contabilidade: teoria e prática (pp. 21-43). São Paulo: Atlas.

Martins, E. (2003). Contabilidade de custos. São Paulo: Atlas.

Martins, G. A., \& Theóphilo, C. R. (2009). Metodologia da investigação científica para ci- 
ências sociais aplicadas. São Paulo: Atlas.

Mauss, C. V., \& Souza, M. A. de. (2008). Gestão de custos aplicada ao setor público: modelo para mensuração e análise da eficiência e eficácia governamental. São Paulo: Atlas.

Monteiro, B. R. P., et al. (2010). O processo de implantação do sistema de informação de custos do Governo Federal do Brasil. Anais do Congresso Informação de Custos e Qualidade do Gasto no Setor Público, Brasília, DF, Brasil, 1.

Rocha, A. V. M. A. (2012). Congresso USP de Controladoria e Contabilidade: hipóteses sobre a presença do debate crítico a partir de uma análise bibliométrica dos trabalhos aprovados. Anais do Congresso USP de Controladoria e Contabilidade, São Paulo, Brasil, 12.

Rosa, M. B. (2011). Contabilidade do setor público: de acordo com as inovações das normas brasileiras de contabilidade. São Paulo: Atlas.

Scarpin, J. E., Söthe, A., \& Kreuzberg, F. (2012). Custos no Setor Público: análise dos artigos posteriores a publicação do estudo n. 12 do IFAC. Revista CAP Accounting and Management, 6(6), 186-201.

Slomski, V. (2011). Controladoria e governança na gestão pública. São Paulo: Atlas. 